\title{
EL SEXO Y LA NORMA: FRENTE ESTATAL, PATRIARCADO, DESPOSESIÓN, COLONIDAD'
}

\author{
Rita Laura Segato \\ Universidade de Brasília
}

\begin{abstract}
Resumen: Paso aquí revista a los diversos efectos de la expansión e intrusión contemporáneas del frente estatal-empresarial - mediático - cristiano, siempre colonial y también para-estatal, en las comunidades indígenas del Brasil - que llamo aquí mundo-aldea - y sus consecuencias para la vida de sus mujeres. Después de este panorama, me detengo en algunos casos y ejemplos que hacen posible percibir los cambios en la mirada sobre la sexualidad y del significado y el valor dados al acceso sexual en las sociedades pre-intervención colonial y en las sociedades intervenidas por el proceso de colonización - en los países hispánicos, la sociedad criolla. La transformación del campo sexual a partir de lo que describo como la introducción de la mirada pornográfica emerge así como fulcro, eje de rotación para la mutación de un mundo en otro. Cuerpo objeto, alienado, y colonia surgen como coetáneos y afines en el nuevo orden en constante expansión. Desposesión, en este proceso, es, por lo tanto, desposesión progresiva del cuerpo y de la sexualidad.
\end{abstract}

Palabras clave: Estado; capital; mujeres indígenas; patriarcado; sexualidad; normas; colonialidad.

\section{Introducción}

Paso aquí revista a los diversos efectos de la expansión e intrusión contemporáneas del frente estatal-empresarial - siempre colonial y también para-estatal - en las comunidades indígenas del Brasil - que llamo en este artículo mundo-aldea - y sus consecuencias para la vida de sus mujeres. Después de este panorama, me detengo en algunos casos y ejemplos que hacen posible percibir los cambios en la mirada sobre la sexualidad y del significado y el valor dados al acceso sexual en las sociedades pre-intervención colonial y en las sociedades intervenidas por el proceso de colonización - en los países hispánicos, la sociedad criolla. La mutación del campo sexual y lo que describo como la introducción de

Copyright $\odot 2014$ by Revista Estudos Feministas.

' Agradezco a Patricia de Mendonça Rodrigues, Mónica Pechincha y Saulo Ferreira Feitosa, interlocutores de referencia para la construcción de este texto. 
la mirada pornográfica emerge así como fulcro o punto nodal, eje de rotación para la mutación de un mundo en otro. Cuerpo objeto, alienado, y colonia surgen como coetáneos y afines en el nuevo orden en constante expansión. Desposesión, en este proceso, es, por lo tanto, desposesión progresiva del cuerpo y de la sexualidad.

\section{"Mundo-aldea" y "frente colonial/estatal - empresarial - mediático - cristiano" en expansión}

Las mujeres indígenas, hoy, viven situaciones de intenso cambio en el continente, y ven, como nunca, a pesar de la multiplicación de leyes, políticas públicas, y de la presencia estatal y de las ONGs, su indefensión aumentar. El proceso político en que se articulan y organizan progresivamente en todos los países intenta colocar un freno a las nuevas formas de violencia y expropiación que enfrentan, pero muchas veces colocando todas las expectativas en las garantías estatales y legales de protección. Las preguntas que aquí intento responder son: ¿Puede el Estado proteger a las mujeres indígenas? ¿Hay indicios de que lo esté haciendo? ¿Por qué caminos debería hacerlo? ¿La situación histórica de las mujeres indígenas, en términos de las privaciones que sufren y de la violencia que soportan, ha mejorado, se ha mantenido estable o ha empeorado con la democratización de los países del continente latinoamericano? Con el propósito de responder esas preguntas, enumeraré aquí, sintéticamente, en forma de lista, la descripción de los daños que emerge de los testimonios recogidos en reuniones oficiales, del movimiento social indígena, y mixtas, en las que convergen representantes de las agencias estatales y representantes de asociaciones de pueblos en Brasil. Considero que Brasil es un campo de observación de esa realidad porque, aun no siendo una nación con mayoría indígena, contaba en 2010 con 305 pueblos, según los datos del Instituto Brasileiro de Geografia e Estatística - IBGE, y casi 900.000 indígenas, según el Censo del Instituto Brasilero de Geografía y Estadística de éstos, 324.834 viviendo en ciudades y 572.083 en áreas rurales - y ha sido escenario, durante la última década, de un proceso riguroso de reordenamiento de la máquina administrativa, y de una expansión vertiginosa de las agencias del Estado y de ONGs en grande medida financiadas por fondos estatales. Ese Estado, que hasta hace veinte años se encontraba ausente en porciones territoriales inmensas del espacio nacional y no era un interlocutor relevante para una fracción numerosa de la población brasilera, se ha tornado, en el curso de una década, fuertemente presente para todas las personas, en todas partes.

En Brasil, las mujeres comenzaron a organizarse en asociaciones exclusivas en los 80 's, con algunas organizaciones de mujeres amazónicas (AMARN y AMITRUT), y continuaron en los años 90's, creándose en 2002, en la ocasión de un primer encuentro de mujeres indígenas amazónicas, un Departamento de Mujeres Indígenas dentro de la influyente Coordinación de Organizaciones Indígenas de la Amazonia Brasilera (DMI/COIAB). De allí en adelante, surgieron organizaciones de mujeres de pueblos indígenas del Noreste y Estados de Minas Gerais y Espíritu Santo (APOINME), de la región Sur y Centro-Sul (ARPIN-SUL). ${ }^{2}$ En medio a esa progresiva articulación política, dos mujeres, Rosane Kaingang ${ }^{3}$ y Miriam Terena, solicitaron, en 2002, al entonces Presidente de la Fundación Nacional del Indio (FUNAI) - organismo estatal que tiene a su cargo la gestión de la vida indígena en el

\footnotetext{
2 Para un panorama de ese proceso, ver las contribuciones publicadas en Verdún 2008

3 El segundo nombre, en lugar del apellido, como es costumbre en Brasil, hace referencia al pueblo de la persona en cuestión, es decir, Rosane es indígena kaingang y Miriam es indígena Terena. Así construiré la mayor parte de los nombres propios en este texto.
}

594 Estudos Feministas, Florianópolis, 22(2): 593-616, maio-agosto/2014 
país -, la realización de un taller en que mujeres de pueblos indígenas de todas las regiones pudieran obtener un vocabulario con conceptos de la teoría de género y una instrucción sobre Derechos Humanos, Derechos de los Pueblos Indígenas y Derechos de las Mujeres, en especial de las mujeres indígenas, y Políticas Públicas de las cuales se pudieran valer. La solicitud tenía carácter de urgente porque eran las vísperas de la asunción del presidente Lula, del Partido de los Trabajadores, a su primer mandato, y se pretendía concluir la reunión con una lista de demandas para presentarle. De esa forma, se organizó un "Taller de Capacitación y Discusión sobre Derechos Humanos, Género y Políticas Públicas" de una semana, a puertas cerradas, en un hospedaje en las afueras de Brasilia, con 41 mujeres de pueblos de todas las regiones del país, y tuve la encomienda de conducir ese taller, que tuvo un formato interactivo. En primer lugar presenté un vocabulario básico de nociones de género y de derechos, acompañando las categorías con algunos casos de la etnografía mundial. A continuación comenzó una conversación fluida e intensa, y a lo largo de esa semana las mujeres indígenas participantes relataron numerosos casos y, por mi parte, intenté ofrecer un léxico que tipificase los casos narrados y las demandas que de ellos emanaban. El ejercicio resultó en un cuadernillo subdividido en dos partes: una primera parte con conceptos básicos de género, derechos humanos y acciones afirmativas en políticas públicas sensibles a la situación de las mujeres indígenas; y una segunda parte con las demandas resultantes de los casos relatados por las mujeres durante la reunión, clasificadas, según el ordenamiento de la gestión pública, como temas de Administración Pública; Educación; Justicia; Seguridad; Salud; Economía y Trabajo; Asistencia Social, Entretenimiento, Deportes y Medios de Comunicación; Medio Ambiente; y Patrimonio Cultural Material e Inmaterial.

Relato esto porque son precisamente testimonios recogidos en esta reunión, así como en las reuniones que le sucedieron, que me dieron acceso a narrativas de casos y quejas que permiten esbozar un perfil de las formas contemporáneas de violencia y sojuzgamiento sufridas por las deponentes, así como también exponen la mutación que experimentaron los tipos de agresión. Es a explorar ese cambio que he calificado de mutación, con toda la radicalidad de la diferenciación a que esta palabra apunta, que voy a dedicar este texto, de forma todavía bastante programática. Me veo obligada a basarme en los relatos recogidos en las reuniones que menciono como mi fuente principal, porque en Brasil no se ha construido, como es el caso en la antropología mexicana ante la interpelación del movimiento de Chiapas, una literatura específica sobre la violencia de género en el mundo indígena que pueda servir de base para un análisis de este tipo, como son también escasas en el país las etnografías que tienen como foco las relaciones de género en las comunidades. ${ }^{4}$ Por otro lado, una publicación tan importante como el Informe del Consejo Indigenista Misionero sobre Violencia Contra los Pueblos Indígenas del Brasil, que viene siendo publicado en forma de Cuaderno desde 1993, no contiene datos sobre violencia específica sufrida por las mujeres indígenas. ${ }^{5}$

Por lo general, este tema queda subsumido en los estudios de parentesco y familia, y hay en general una reserva muy grande en el medio de los etnólogos brasileros en cuanto a la cuestión de género en el mundo indígena, pues el consenso aún dominante en el campo es que ese tema introduce una beligerancia y una política - de minorías, de

\footnotetext{
${ }^{4}$ Ver, por ejemplo, el dossier publicado por la Revista de Estudos Feministas de 1999, dedicado al tema, con una presentación de Bruna FRANCHETTO y artículos de Cristiane LASMAR, Vanessa Rosemary LEA, Cecilia MACCALLUM y Patricia de Mendonça RODRIGUES. También ver: Bruna FRANCHETTO, 1996; Angela SACCHI, 2003; Cristiane LASMAR, 2005; Patricia de Mendonça RODRIGUES, 1993 y 2008; Fabiane Vinente dos SANTOS, 2012; y Maria do Rosário CARVALHO, 2013.

${ }^{5}$ CENTRO INDIGENISTA MISSIONÁRIO, 2011.
} 
derechos humanos, de derechos de las mujeres - espurias y sobreimpuestas desde el exterior de la visión de mundo amerindia.

Una vez concluida la experiencia del primer taller, la cartilla resultante, ${ }^{6}$ con su lista de demandas, permitió reivindicar con éxito, frente al Ministerio de Planificación, fondos para proseguir con una secuencia de reuniones de mujeres indígenas de diversos pueblos, que pasaron entonces a ser realizadas por región. En 2007 la FUNAI crea la Coordinación de Mujeres Indígenas, en 2008 se la transforma en Coordinación de Género y Asuntos Generacionales (COGER), pasando a incluir la gestión de los temas de las juventudes indígenas, y en 2012 vuelve ampliarse para incluir la gestión de la Movilización Social y pasa a llamarse Coordinación de Género, Asuntos Generacionales y Movilización Social (COGEM). Este órgano, desde su creación y a través de sus transformaciones, siempre estuvo a cargo de una mujer indígena, Léia Bezerra Vale Wapichana.

A partir del taller de 2002, que fue nacional y generalista en su amplitud geográfica y de contenidos, la cuestión de la mujer y de las relaciones de género se estableció como temática dentro del órgano indigenista oficial, y se pleitearon y lograron los fondos que permitieron, a partir de la ocasión, una gestión con perspectiva de género, y más tarde la consolidación de una coordinación específica. Dos series de talleres se realizaron. La primera, hasta 2006, tuvo por foco el apoyo a las actividades productivas a cargo de las mujeres en las comunidades, con el supuesto de que fomentar los trabajos de las mujeres sería reforzar la posición de las mismas en sus respectivas comunidades. En 2006, se ratificó en Brasil la Ley Maria da Penha contra la Violencia Doméstica. También en 2006, se realizó en Brasilia un Encuentro Nacional de Mujeres Indígenas con la participación de 28 mujeres de varios pueblos de todas las regiones. A partir de 2007, una nueva serie de talleres regionales pasó a realizarse, ahora con foco en la divulgación de la nueva ley entre las mujeres indígenas. A partir de 2011 , y hasta el presente, se iniciaron experiencias, con una primera reunión piloto ocurrida ese mismo año para intentar alcanzar a los hombres de las sociedades indígenas y ganarlos como aliados en la estrategia para la disminución de la violencia, tal como las mujeres indígenas habían repetidamente solicitado. Ciertamente, no fue una tarea fácil, porque se trata de un mundo compartimentado en términos de género. Esto quiere decir que hombres hablan con hombres, y mujeres hablan con mujeres. Respetar esta diferencia del "mundo-aldea", fue y es una pauta ineludible. Finalmente, en junio de 2013 se realizó el primer encuentro de una nueva serie dirigida a los hombres indígenas de la región Noreste del país.

Desde el primer taller inicial, que conduje en 2002, surgieron los relatos que permitieron tipificar los tipos de violencia sufridos en la actualidad por las mujeres indígenas, y esos tipos se repitieron de forma casi idéntica en todas las reuniones siguientes, reportados por las mujeres para las diversas regiones y asociados precisamente a la localización de los territorios indígenas: aldeas en regiones fronterizas con presencia de destacamentos militares que custodian la soberanía nacional, aldeas en regiones fronterizas afectadas por el tráfico de drogas, aldeas afectadas por el tránsito de traficantes, aldeas próximas a locales donde se procesa droga, aldeas localizadas en santuarios naturales remotos, aldeas vecinas a zonas de protección ambiental o que se superponen a las mismas, aldeas en regiones de expansión del agro-negocio, aldeas en regiones con atractivos turísticos y emprendimientos hoteleros, aldeas en regiones de yacimientos de piedras preciosas, aldeas en regiones de yacimientos de minerales de interés estratégico, aldeas en regiones próximas a yacimientos de hidrocarburos, aldeas en regiones en que se proyectan o construyen usinas hidroeléctricas, aldeas próximas a rutas nacionales y estaduales, aldeas localizadas en

${ }^{6}$ SEGATO, 2003a.

596 Estudos Feministas, Florianópolis, 22(2): 593-616, maio-agosto/2014 
las periferias urbanas o englobadas por las ciudades en su expansión, comunidades desaldeadas e indios urbanos.

En cada una de estas localidades, las mujeres sufren formas particulares de agresión y desposesión; su subjetividad y su corporalidad cambian de significado y pasan a ser agredidas y apropiadas de forma nueva. Las jerarquías de género propias de la vida en comunidad, que he descripto como "patriarcado de bajo impacto" por razones que examinaré más tarde, se transforman en el patriarcado moderno, de alto impacto, y de muy ampliada capacidad de daño. Haciendo uso de una nomenclatura que necesita de pocas explicaciones por ser auto-evidente en buena medida, podemos decir que el "mundoaldea", con el tejido de relaciones comunitarias que le son propias, como volveré a insistir, se encuentra atropellado por el azaroso camino de la expansión vertiginosa del "frente colonial/estatal - empresarial - mediático - cristiano". Esto no significa meramente el cambio del telón de fondo, de la escenografía de su existencia, sino un atravesamiento de la misma por prácticas y poderosos discursos que se respaldan y afirman en los valores dominantes del desarrollo y la acumulación, la productividad, la competitividad y el cálculo costo-beneficio propios de la economía de pleno mercado y su "teología", es decir, la fe absoluta en la inescapabilidad de su destino e irreversible expansión, como valor eurocéntrico de un mundo que "progresa".

Se trata, sin duda, de una novedad. Esta irrupción que atropella el mundo-aldea captura todos los elementos de su vida comunitaria de antaño, los engloba y reconfigura dentro y como componentes de un nuevo programa; es una nueva vuelta, un reciclaje, pero con dimensiones antes desconocidas, de lo que fue la primera embestida colonial que siguió inmediatamente al proceso de conquista, así como también difiere, por su naturaleza, de la fase republicana de expansión de los recién creados Estados nacionales sobre los territorios del indio. Es un proceso que da continuidad a aquellas embestidas de expansión precedentes, pero ahora, insisto, en una etapa cualitativamente diferente, caracterizada por la existencia consolidada de un mercado global que compite, agrede y erosiona los mercados regionales y locales; por gobiernos centrales de todas las orientaciones que aspiran a inscribir las economías nacionales bajo su administración en el horizonte de ese mercado global; y por la expansión de la esfera pública, el lenguaje de derechos y políticas ciudadanas introducidas en el mundo-aldea por organismos estatales y organizaciones no gubernamentales.

Aunque pueda parecer que estas facetas de la contemporaneidad se encuentran en tensión, es decir, aunque pueda pensarse que el pacto estatal-empresarial que abre las puertas a la agresión del mercado global es contradictorio con la expansión de los derechos y servicios ciudadanos en el mundo-aldea, ellos no constituyen, como pensamos a menudo, términos antagonistas, y sí facetas de un proceso coetáneo y complementario: la colonización económica y la colonización por el discurso de los derechos y de la esfera pública. De este tipo de estructura internamente contradictoria nos habla Gil Gott, ${ }^{7}$ en su brillante análisis de la "dialéctica aprisionada" (arrested dialectics). En la situación contemporánea, como he afirmado, el estado ciudadano va a remolque del estado empresarial, y ambos amparados por la representación mediática. En ese camino, una mano intenta, con torpeza, ir remediando los males que la otra mano va sembrando; la mano del Estado ciudadano intenta amenizar las mortandades que el pacto estadoempresa origina y patrocina en su camino arrollador, causando un daño en espiral, porque el lenguaje de los derechos ya se encuentra dentro del lenguaje de la modernidad, del desarrollo, el progreso entendido unilateralmente como capacidad de acumulación,

7 Gil GOIT, 2002. 
eufemísticamente descripta como "crecimiento'. Con una mano introduce el mal, con la otra le inocula la vacuna. Dos caras de la misma moneda, en una tensión que se resuelve, definitivamente, a favor de la profundización del patrón de la colonialidad. Colonialidad entendida aquí con un sentido todavía más preciso, en el contexto de esta modernidad y capitalismo avanzados.

\section{Cambios en el patrón de la victimización de las mujeres indígenas}

En forma de lista, se enumeran a continuación las modalidades de violencia que alcanzan a las mujeres indígenas hoy. El acento fue colocado en las agresiones directas o indirectas que son características para cada tipo de región en que se encuentran las comunidades, y bajo la presión de la transformación de los contextos locales como efecto de la expansión del frente estatal - empresarial. Estas modalidades de violencia fueron reiteradas, de forma casi idéntica, en todas las reuniones en que participé. Aquí las sistematizo y enumero de forma compacta, convencida de que el proceso que arrolla y masacra la vida de las mujeres indígenas en el Brasil contemporáneo se torna auto-evidente con el solo pasar la vista, en una lectura sumaria del listado a seguir.

Aldeas en regiones fronterizas con presencia de destacamentos militares que custodian la soberanía nacional:

- atracción engañosa al matrimonio y abandono después del traslado de los efectivos militares;

- atracción a la práctica de prostitución mediante engaño;

- atracción al servicio doméstico esclavo o semi-esclavo en las casas de oficiales y suboficiales;

- introducción de la mirada pornográfica y alienante sobre el cuerpo indio;

- violaciones;

- violencia doméstica exacerbada por la presencia disruptiva y la presión ejercida en la vida cotidiana por los destacamentos militares en las inmediaciones;

- influencia sobre los hombres indígenas de los modelos de virilidad propios de la cultura masculina de los destacamentos militares.

Aldeas localizadas en santuarios naturales:

- asedio por parte de misioneros cristianos bien equipados tecnológicamente que tienen, desde la primera mitad del siglo XX, acceso privilegiado y exclusivo a estas regiones $y$, con su merodeo e ingreso forzado a la vida de la aldea, transforman disruptivamente las relaciones de autoridad y los patrones cosmológicos que sirven de referencia a las relaciones de género;

- consecuente interferencia en las concepciones de sexualidad y en la vida de pareja y matrimonial;

- introducción disruptiva y prejudicial de ideas de pecado y malignidad asociadas al cuerpo femenino y a la sexualidad con consecuentes prejuicios morales misóginos y homofóbicos que afectan a la posición de la mujer y de los homosexuales en el contexto comunitario;

- introducción de la equivalencia, de cuño occidental, entre acceso sexual y "hacer daño";

598 Estudos Feministas, Florianópolis, 22(2): 593-616, maio-agosto/2014 
- introducción de la exterioridad de la mirada sobre el cuerpo propia de la metafísica occidental y cristiana y conducente a la pulsión escópico- pornográfica, antes inexistente en el mundo amerindio.

Aldeas en situación de aislamiento voluntario o con poco tiempo de "contacto"8 que se encuentran bajo la mira del agro-negocio y de los grandes proyectos hidroeléctricos:

- la vida en permanente tensión y estado de alerta para la fuga, así como el miedo constante de ser capturados por los emprendimientos del frente estatal - empresarial en expansión lleva al grupo, y en especial a las mujeres, a no concebir más hijos, provocando el riesgo de extinción de la sociedad.

Aldeas reconstituidas por el propio Estado Nacional mediante remoción, relocalización y reagrupamiento aleatorio de comunidades para permitir la construcción de estradas, la instalación de emprendimientos agrícolas o la construcción de usinas hidroeléctricas en sus territorios:

- Reagrupación y abandono de pueblos ancestralmente enemigos en nuevas aldeas dejando a las mujeres expuestas a la captura y violación tanto por parte de los hombres blancos a cargo del "frente de atracción" que "atrajo", aprisionó y relocalizó las comunidades, como por parte de los hombres de la sociedad enemiga con quienes fueron obligados a compartir el nuevo asentamiento

- configuración de una situación para-concentracionaria que dejó tanto para las mujeres que sobrevivieron al proceso y como para las que nacieron del mismo las alternativas únicas del celibato, los relacionamientos breves y estigmatizantes, o relacionamientos estables con hombres violentos y alcohólicos;

- intervención estatal, a cargo de los "frentes de atracción" o de las autoridades a cargo de los nuevos asentamientos, que impuso el apareamiento y la reproducción forzada de mujeres con hombres de otros pueblos;

- interferencia autoritaria en el derecho de elección de cónyuges, y del modo de la socialización de los hijos por parte de agentes de la asociación público-privada del Estado, especialmente con compañías hidroeléctricas.

\section{Aldeas en regiones de expansión del agro-negocio:}

- expropiación de territorios y expulsión de las comunidades localizadas con la consecuente disrupción de la vida familiar y del tejido colectivo y la introducción de tensiones antes desconocidas en la vida doméstica;

- gansterismo patrocinado por los propietarios y aspirantes a propietarios para introducir el terror, por medio de ejecuciones selectivas y masacres, amenazando especialmente a los hombres e impidiendo que éstos se desempeñen en su rol masculino habitual de proteger la vida de mujeres y niños en las comunidades;

- corrupción activa de sus liderazgos y autoridades políticas y religiosas, con consecuente ruptura de las formas de convivencia y cooperación entre los géneros, e ingreso de modelos de virilidad extraños y distanciados de los códigos y prácticas comunitarios;

- atracción de los hombres al trabajo en los emprendimientos agropecuarios y a cargos políticos y de servicios remunerados en los municipios, con consecuente exposición a modelos de virilidad que les son propios y que erosionan los patrones indígenas de relación y complementariedad entre los géneros;

${ }^{8}$ Datos del Centro Indigenista Missionário - CIMI indicaban que en 2010 eran 90 los pueblos en esa situación. 
- ruptura de las lealtades de los hombres para con sus respectivas familias o imposibilidad de cumplir con las demandas propias de esas lealtades;

- emasculación de los hombres indígenas por incapacidad de cumplir con sus responsabilidades de género y consecuente recurso por parte de éstos a la exacerbación de la agresividad y la capacidad violenta como estrategia de restauración de su imagen masculina decaída;

- escalada de la violencia de género como consecuencia de la inducción al desaliento y a la depresión, al suicidio, a la dependencia química y a la autodestrucción de los jóvenes por el sentimiento de indefensión e impotencia resultantes de la amenaza y el terror constantes, los asesinatos de líderes, la restricción de recursos, la facilitación del acceso a bebidas alcohólicas, la dependencia alcohólica promovida;

- enajenación en la vida familiar y comunitaria, y escalada de la violencia en los espacios doméstico y público por la exacerbación de la presión sobre los miembros de las comunidades y su efecto psicológico;

- nuclearización progresiva de la familia como consecuencia de la creciente influencia del modelo de la familia occidental y colonial/moderna, con el consecuente debilitamiento del control comunitario y de las autoridades indígenas sobre la vida familiar;

- desgaste y quiebra de la capacidad mediadora y del prestigio de los liderazgos indios, con desarticulación del tejido comunitario y el fin de la salvaguarda que él representa para la protección de las mujeres.

Aldeas vecinas a zonas de protección ambiental o que se superponen a las mismas:

- imposición de límites muy precisos a la necesidad cíclica de cisión de las comunidades por conflictos internos, con consecuente sellamiento de los conflictos en el interior de las comunidades;

- exacerbación de las tensiones domésticas por el impedimento de que grupos en conflicto puedan dividirse y sus partes disidentes trasladarse a locales próximos, formando nuevas aldeas.

\section{Aldeas en regiones con atractivos turísticos y emprendimientos hoteleros:}

- intrusión en los territorios y consecuente introducción de factores de stress en la vida comunitaria y doméstica;

- captación de indígenas para las tareas de construcción de establecimientos hoteleros y servicio en sus instalaciones cuando ya en funcionamiento, con consecuente abandono de sus actividades habituales y exposición a una economía mercantilizada y a modelos de género ajenos a sus patrones de existencia;

- fuerte introducción de la moneda y fetichización y mercantilización de los componentes del modo de vida indígena y de su ambiente natural, incluyendo la comercialización de la imagen corporal de mujeres y hombres indígenas con la consecuente objetificación de los cuerpos;

- captación de mujeres indígenas para la prostitución.

Aldeas en regiones de yacimientos de piedras preciosas:

- intrusión del medio por aventureros que actúan sin referencia a normas y tienen un impacto disruptivo en la vida comunitaria y doméstica;

- ocupación de territorios mediante prácticas de gansterismo y amedrentamiento, sembrando el terror por medio de ejecuciones selectivas y masacres; 
- convocación a un modelo de virilidad que es extraño a las relaciones de género comunitarias:

- atracción de las mujeres para obtener servicios sexuales, promoción de la prostitución;

- violaciones;

- concubinatos interétnicos disruptivos para las reglas comunitarias;

- como en todos los casos, la presión intrusiva sobre el grupo promueve el stress y la agresividad en el espacio doméstico y comunitario;

- conflictividad y enfrentamientos abiertos entre garimpeiros explotadores de los yacimientos y las comunidades, con severa victimización de las mujeres en el contexto bélico que así se origina.

Aldeas en regiones de yacimientos de minerales de interés estratégico, de yacimientos de hidrocarburos y aldeas en regiones en que se proyectan o construyen usinas hidroeléctricas:

- intrusión por emprendimientos de sondeo y exploración del subsuelo que introducen personas ajenas a la comunidad, con sus pautas propias de relacionamiento incluyendo el género, sus valores basados en un desarrollo definido por el productivismo, la competitividad y la capacidad de acumulación, y sus modelos de agencia viril asociados a esa relación de exterioridad con relación a un medio natural y humano entendido exclusivamente como oportunidad para la extracción de lucro y ventajas: una pedagogía del cuerpo y de la naturaleza alienables, presa disponible para la apropiación, el control jurisdiccional y la explotación hasta el desecho, objetificación que incide en la percepción de las mujeres como cuerpo a ser apropiado y rapiñado;

- los campamentos de las instalaciones extractivistas y de las represas destinadas al sondeo, construcción de grandes obras y el gerenciamiento de las mismas incluyen vigilancia privada que, como parte de sus estrategias "defensivas" realiza acciones de intimidación que incluyen ejecuciones selectivas, amenazas y masacres, interviniendo en la región de forma disruptiva e introduciendo alto grado de stress y tensión en las relaciones comunitarias y familiares de los indígenas habitantes de la región;

- alcoholismo derivado de la presencia del frente blanco, con el resultado de la violencia que la enajenación alcohólica, sumada al stress causado por la intrusión e intervención en el tejido comunitario, provoca en las relaciones familiares;

- instalación de casas nocturnas y prostíbulos en el perímetro de las empresas y, en algunos casos, dentro de sus instalaciones, con la consecuente oferta de bebidas alcohólicas y del cuerpo femenino ofrecido como objeto a ser abordado desde una exterioridad apropiadora y mercantil.

Aldeas en regiones fronterizas afectadas por el tráfico de drogas y aldeas afectadas por el tránsito de traficantes:

- reclutamiento de jóvenes para el tráfico y el impacto de esta forma de empoderamiento masculino sobre las relaciones de género;

- oferta de enriquecimiento y nuevas formas de control de la vida social por medio del dinero y consecuente impacto negativo de esta forma de empoderamiento masculino sobre las relaciones de género;

- oferta de armas para ejercicio del control territorial y exacerbación de la violencia, con consecuente impacto en las relaciones de género y la vida doméstica; 
- formación y proliferación de gangs vinculadas al tráfico con sus códigos y prácticas de competitividad y espectacularización de la crueldad propios basados en un estilo mafioso de virilidad;

- introducción disruptiva de armas y drogas en la aldea asociadas al control territorial y a la exhibición de capacidad violenta con consecuente victimización de las mujeres;

- aplicación de castigos y tratamiento cruel con fines de ejemplaridad para el control jurisdiccional y afirmación viril de los jefes;

- proliferación de violaciones en el espacio público y violaciones domésticas;

- disrupción e inversión de la jerarquía de autoridad tradicional basada en las franjas etarias con consecuente reducción de la capacidad de control y mediación por parte de las autoridades indígenas;

- violencia doméstica exacerbada por la introducción de un nuevo modelo de virilidad propio de las organizaciones mafiosas.

Aldeas próximas a rutas nacionales y estaduales, y grupos de indígenas sin territorio propio acampados en los márgenes de carreteras:

- intrusión y desarticulación de las pautas de vida comunitarias por parte de la sociedad no indígena, causando stress y desorientación en las relaciones de género y familiares;

- proximidad de prostíbulos y del accionar de la trata de personas y del tráfico;

- introducción de la mirada objetificante y pedagogía del cuerpo-objeto;

- atracción al alcoholismo y las drogas, con su consecuente efecto violentogénico y ruptura de códigos;

- en condiciones de carencia, falta de acceso a la salud y a la educación, a la alimentación, al agua y al saneamiento básico, en los grupos acampados de indígenas sin territorio propio, la autoridad parental sufre la pérdida de la guardia de sus hijos debido a que las familias son acusadas por los agentes estatales de maltrato o falta de cuidado;

- en lugar del Estado, los padres son castigados con la pérdida de sus hijas e hijos, que son retirados de las familias y entregados en adopción en las ciudades próximas;

- las niñas se encuentran, en esos asentamientos transitorios en el margen de las carreteras, en situación de extrema vulnerabilidad y expuestas a la violencia sexual y a varias formas de explotación;

- alta incidencia de suicidios en niñas y adolescentes. ${ }^{9}$

Aldeas localizadas en las periferias urbanas o englobadas por las ciudades en su expansión, comunidades 'desaldeadas' e indios urbanos:

- Carencia de todo tipo de acceso a derechos específicos y políticas públicas especializadas por parte de las mujeres indígenas en esta situación, negados a ellas, por un lado, por municipios que dicen no atender la salud, la educación o la asistencia social de indígenas, y, por el otro, por los órganos estatales indigenistas, que no reconocen a los indígenas 'desaldeados' como tales;

- explotación sexual infantil y casos de esquemas organizados por comerciantes locales para la victimización sexual de las jóvenes indígenas;

\footnotetext{
${ }^{9}$ Aunque el suicidio es mayor entre hombres, hay un número alto de suicidios de mujeres jóvenes y niñas entre los Guarani Kaiowá.
} 
- retención de documentos de mujeres embarazadas o madres recientes para el cobro de pensiones y auxilios estatales.

Todas las comunidades indígenas del país:

- desarreglo de las relaciones de género por exposición de los hombres al modelo de virilidad criollo, colonial/moderno;

- introducción de la mirada pornográfica y objetificante sobre el cuerpo;

- aumento de la frecuencia y del grado de crueldad de la violencia de género en sus diversas modalidades, tanto intrafamiliar como extra-familiar;

- vulnerabilidad de las mujeres al asedio sexual por parte de agentes estatales asalariados que actúan como maestros y profesores, agentes sanitarios, fuerzas de seguridad, etc., aun cuando estos sean también indígenas;

- vulnerabilidad de las mujeres al alcoholismo y uso de drogas por parte de sus parejas o por ellas mismas.

Aldeas en estado de guerra con los invasores o alcanzadas contemporáneamente por el asalto bélico sobre sus territorios:

A esta larga lista de formas de vulneración de la vida y el bienestar de las mujeres, a medida que avanza la desposesión de sus pueblos, se agrega una forma de violencia extrema asociada a las formas contemporáneas de la guerra, como el ocurrido ejemplarmente en lo que se llamó, en Brasil, Masacre del Paralelo 11. La codicia por el yacimiento de diamantes, uno de los diez mayores del mundo, que abriga la Tierra Indígena Roosevelt, de 2, 6 millones de hectáreas en los Estados de Rondonia y Mato Grosso, llevó a incursiones y expediciones punitivas constantes de "garimpeiros" - mineros artesanales - aliados a "siringueros", contra los indios Cinta Larga, dueños ancestrales de ese territorio. En 1963 tuvo lugar uno de los episodios más crueles de esa invasión: enviados de la empresa Arruda \& Junqueira, después de arrojar azúcar envenenada y dinamita a una aldea en fiesta desde un avión alquilado por la empresa, persiguieron a los indios y, al localizarlos en las proximidades del Paralelo $11^{\circ}$, los asaltaron, matando a un grupo con formas extremas de crueldad. Entre estos, una mujer fue colgada viva y cortada al medio con un facón. ${ }^{10}$ Esto configura lo que he venido categorizando como un crimen de femigenocidio, por el carácter plenamente público y el contexto bélico en que ocurrió. ${ }^{11}$ Recuerda, por sus características, a los crímenes cometidos contra las comunidades indígenas de Guatemala en el cuerpo de sus mujeres, exterminadas con extrema crueldad como forma de exhibir espectacularmente la capacidad violenta sin límite, el dominio territorial y la soberanía sobre la vida en la jurisdicción en disputa, característica modalidad operativa en las nuevas formas de la guerra. ${ }^{12}$

En Argentina, Silvana Sciortino registra, en su etnografía junto a mujeres indígenas reunidas en el movimiento de mujeres, una serie de testimonios que refieren a situaciones de violencia ejercida contra las mujeres. En los espacios de debate que las indígenas conforman en el marco de los Encuentros Nacionales de Mujeres, muchas de ellas se animan a describir situaciones de violencia en sus comunidades, en las ciudades y en espacios de movilización social. Entre algunas de las situaciones se mencionan: violaciones en contexto de trabajo doméstico perpetradas por el patrón, en sus comunidades ejercida la violencia por varones indígenas o por "criollos" o "winkas", así como violaciones a las jóvenes indígenas que

10 João DAL POZ y Carmen JUNQUEIRA, 2013.

11 Rita SEGATO, 2011

12 SEGATO, 2006. 
migran a las urbes por trabajo o estudio; violencia doméstica asociada principalmente al problema del alcoholismo; muertes por abortos clandestinos; maltrato, abuso e imposición de prácticas médicas; dificultad para el acceso a la participación política y la toma de la palabra; imposición de modelos occidentales de belleza. ${ }^{13}$

Este panel y la variedad de situaciones en él compiladas habla por sí mismo al respecto de las metas y alianzas de un Estado que ve en los territorios habitados por los pueblos indígenas no más que una ocasión para dar continuidad a la rapiña colonial. A partir de un cuadro de atrocidades como el aquí trazado es posible concluir que el proyecto del Estado nacional no es otro que el de un frente de explotación del territorio para el que se coadunan instituciones estatales con el interés empresarial en expansión. Se trata, sin duda, del lado más sombrío de la modernidad, siempre imbuida de su naturaleza colonial. Una colonial/modernidad, como nos ha hecho notar Aníbal Quijano, a partir de la fundación colonial del proceso moderno y del propio capitalismo. ${ }^{14}$ Por lo tanto, no son emprendedores privados los que afectan la vida del indio y transforman en un verdadero calvario la existencia de las mujeres indígenas, pues estos emprendedores no podrían existir sin una alianza y un respaldo estatal.

Es a remolque de este daño permanente y consistente que el Estado saca a relucir su capacidad legislativa, pero siempre lado a lado con el daño o con posterioridad al mismo. En la ambivalencia inevitable del Estado, determinada por la naturaleza francamente incompatible de su pretensión democrática con su adhesión al proyecto del capital, radica la clave del fracaso de sus políticas reparadoras. Es así que podemos repetir lo que ya hemos afirmado otras veces al observar el proceso de avance del frente estatal-empresarial: que el Estado y la modernidad que representa intentan ofrecer con una mano lo que ya han retirado con la otra, y por la precedencia y la magnitud del daño, que además no se detiene, la mano reparadora - izquierda en todas las alegorías - es siempre más débil que la agresora.

\section{Mundo Aldea y sociedad colonial/moderna: normativa y sexualidad como bisagra de su diferencia}

No resulta fácil la tarea de desentrañar y exponer el carácter permanentemente colonial del frente estatal y la manera en que, con su avance, interviene y descompone la malla comunitaria del mundo-aldea, pues se trata de una intrusión molecular, que se apodera de las estructuras en las que gravita todo un ordenamiento de la vida, y las transforma carcomiéndoles el meollo y dejando la carcasa hueca. Esa carcasa, o superficie de las instituciones de la vida social, presenta una apariencia de continuidad y permite, por ejemplo, seguir hablando de relaciones de género, de normas del grupo, de "autoridad tradicional", o de sus "costumbres", produciendo un espejismo de continuidad histórica entre el mundo-aldea antes y después de su intervención por el frente colonial con la interceptación de su historia por el proyecto histórico moderno. Por detrás de una apariencia de continuidad de algunas estructuras, como paradigmáticamente el género, se esconde una ruptura, una verdadera mutación. Nomenclaturas permanecen, pero ahora imbuidas de un sentido muy distinto, por haberse incorporado a una nueva lógica, a un nuevo orden que es el orden de la colonial/ modernidad. Ocurre entonces el efecto de una verosimilitud de lo que llamamos género y de lo que llamamos ley propia del mundo-aldea, cuya

\footnotetext{
${ }^{13}$ Ver los debates de las mujeres indígenas en Argentina en torno a la incorporación de la violencia de género como tema en la agenda política de sus pueblos en Silvana SCIORTINO, 2012.

${ }^{14}$ Aníbal QUIJANO, 1991a y b, entre otros, y SEGATO 2014a.
} 
consecuencia es una normativa que nos parece atroz, pero que, mirada con más aproximación, nos revela el engaño de nuestra lectura inicial. ${ }^{15}$

Nos traiciona también la propensión generalizada a dejarnos enceguecer por el engaño de las retóricas de la modernidad y la fe no examinada en el Estado, la esfera pública, las leyes y, en fin, las instituciones de la modernidad, que nos conducen, incautos, a una alterofobia ${ }^{16}$ y a una desconfianza visceral de los otros mundos, de los mundos noblancos. También algunos feminismos son alcanzados aquí, con esta crítica, en su ceguera propia. Son aquellos feminismos universalistas, que no perciben que la propia sexualidad, que el acceso sexual mismo, tiene significaciones muy distintas, constituyéndose inclusive en el pívot de la mutación de los mundos con la entrada de la mirada colonial/moderna, siempre objetificadora, rebajadora y pornográfica, como intentaré demostrar con el relato de algunos casos. De la misma forma, se critican aquí ciertos pluralismos, incluyendo algunas vertientes del pluralismo jurídico que, aun bienintencionadamente, positivan la norma, el mito y las cosmologías, fundándose en un relativismo cultural esencialista y metafísico que no contempla el pluralismo histórico, el cual, como he afirmado en otra parte, es la dimensión más radical del derecho a la diferencia. ${ }^{17}$

Un breve examen de algunos ejemplos de cómo se malentiende el tránsito de estructuras de un mundo a otro cuando no se tienen en cuenta las debidas mediaciones servirá aquí para mejor comprender lo que expongo. Mucho se ha hablado del pleito de las mujeres contra la ley consuetudinaria de numerosas sociedades tribales de países africanos como Sudan, Zambia, Uganda, Nigeria y Zimbabue, que les prohíbe heredar de sus mayores o de sus cónyuges. En 2012 fue muy celebrado un fallo de un juez de Botsuana que permitió a dos hermanas recibir la herencia de la casa paterna. El debate, allí, con gran ceguera histórica, se coloca en términos de la oposición entre la barbarie de una ley interna que impide a las mujeres heredar y las transforma en parias, y el carácter "civilizado" de una ley moderna que debe prevalecer imponiendo la igualdad de Derechos. El debate omite, sin embargo, que un mal precede a la barbarie del enunciado contemporáneo de la "ley tribal". Esa omisión se debe a la forma en que en el precepto moderno descomponemos la vida, fragmentando sus componentes como si estos fueran pasibles de ser observados separadamente. De hecho, una norma de herencia patrilineal existe asociada e indivisible de otras normas de vida comunitaria que garanten el goce colectivo del patrimonio.

El primer error, entonces, no es la prohibición de la herencia por parte de las mujeres, sino la disolución del colectivo. Sin embargo podemos hablar aquí de una ceguera instrumental, pues ve la barbarie de dejar a las mujeres en estado de desposesión, pero no ve la barbarie de la desarticulación colonial/moderna de la vida comunitaria, y mucho menos se preocupa por crear los mecanismos necesarios para restaurar el tejido colectivo damnificado. Cuando hablamos, por lo tanto, de ley tribal, no podemos olvidar de la forma holista en que ésta es concebida y funciona, en articulación y conexión indisociable de normativas referidas a todos los aspectos de la vida comunitaria y sin permitir el aislamiento de una regla particular, como en este caso la regla de la herencia.

Otro caso muy revelador de este malentendido generalizado que nos lleva a apostar todas las fichas a la ley moderna y al avance del Estado como benefactores del indio se puede entender a partir de una impresionante historia que me fue relatada por la profesora xavante Isabel Rê'amo Wadzatsé de la Aldea Imaculada Conceição, situada en la Tierra Indígena São Marcos. En el mundo amerindio, a diferencia de la ley moderna, la violación

\footnotetext{
15 SEGATO, 2014b.

${ }^{16}$ Álvarez DEGREGORI, 2001.

17 SEGATO, 2014C.
} 
no es un crimen sino una forma de castigo, una figura de la ley consuetudinaria que establece que determinadas contravenciones de parte de las mujeres tienen como punición la violación colectiva. Desde una perspectiva moderna, cuesta entender que por décadas, hasta recientemente, los antropólogos que visitaron aldeas distantes supieron de la existencia de esta sanción pero no tuvieron jamás ocasión de verla o saberla aplicada. Como dije, se trataba, más que nada, de una figura del discurso jurídico interno que colocaba un firme límite en posibles infracciones femeninas como, por ejemplo, espiar los secretos de la iniciación masculina en la casa de los hombres.

Sucede que, con la intrusión de la concepción burocrática moderna de lo que es una norma jurídica, la ley se especializó y se mecanizó: no existen, en principio, normas que no sean aplicables, la ley deja de ser entendida como una figura del discurso, aunque, de hecho, con frecuencia, lo continúe siendo. El caso que me relató la profesora Isabel vino a mostrarme, justamente, este dramático cambio en el papel y la función de la ley, en su sentido. En una familia de su aldea xavante, una joven casada cometió adulterio con un indígena del mismo pueblo, habitante de la ciudad. El indígena que sedujo a la joven había sido cooptado y corrompido por la sociedad blanca y ocupaba un cargo político electoral en el municipio. Mantuvo un relacionamiento con ella, y luego la abandonó. La joven, entonces, pidió para retornar a su casa, su joven marido la perdonó y le abrió las puertas para que retornase y sus padres también estuvieron dispuestos a recibir a la joven de vuelta. Pero la ley tribal se había vuelto automática, caso la joven volviese, 200 jóvenes guerreros la violarían, aplicando maquinalmente y otorgando materialidad a lo que antes siempre había sido una fórmula del discurso.

Hoy, según me cuenta la profesora Teresa y otras participantes xavantes de los talleres de divulgación de la ley Maria da Penha contra la violencia doméstica, se han multiplicado los casos de violación en las aldeas, y lo que antes era una forma de amenazar y amedrentar, se materializa regularmente. Sociedades que siempre presentaron los más bajos índices de violación, son hoy sociedades con índices altos de violación, por no otra razón que una mutación en el significado y el papel de la ley. Por lo tanto, es importante comprender que cuando decimos "ley interna", derecho consuetudinario, no deberíamos estar hablando de normas que se burocratizan e independizan para recaer con su sanción como un deus ex-maquina desde el exterior del contexto particular, sino de leyes que juegan un papel de otro tipo en el juego de las narrativas que se entrecruzan en el cotidiano de una comunidad indígena.

Con la aclaración, todavía, de que, al hablar de una pena de violación, el segundo término, es decir, la violación misma, no tiene el mismo valor y significado que el mismo acto adquiere en la sociedad moderna, pues la sexualidad se organiza y se encamina de otra forma. La violación no tiene el sentido de un asesinato moral, de un daño a la moral, que destruye el prestigio y el valor de alguien. No hay vergüenza ni perversidad endosados en la agresión sexual, y ésta no deshonra a la víctima y sus figuras tutelares. La agresión sexual es una entre otras posibles, un castigo corporal pero no un castigo moral, y no constituye una reducción moral de la víctima y, a través de ella, de su familia y comunidad enteras, como es el caso en el occidente moderno.

En ambos casos, tanto en el de la ley que interdice la herencia femenina como en la norma que sanciona la punición por violación estamos frente a la típica maniobra moderna, que pinza un elemento y lo desarraiga de su contexto originario, imponiéndole una torsión que hace con que el elemento mantenga su apariencia - ley, norma, sanción, punición, en estos dos casos-, pero el contenido de ese nombre y la significación de ese elemento se encuentre cambiado. Un nuevo sentido es contrabandeado como referente de una denominación que continúa. Y detenernos aquí para puntualizar este efecto de verosimilitud 
y falseamiento del sentido original de las normas es muy relevante para entender qué sucede con las reglas que orientan las relaciones de género a partir de la interferencia del frente colonial sobre el mundo-aldea, es decir, cuando la masculinidad propia del mundo aldea se ve interpelada y convocada por la masculinidad del mundo colonial/moderno y debe responder a éste en la guerra, la negociación de la paz, la política y la oferta de trabajo.

En el campo del Derecho y de la Antropología Jurídica, esta crítica ha sido enunciada con eficiencia por Esther Sánchez Botero, en un largo examen de lo que ocurre y no debería ocurrir al intentar realizar el, en principio, saludable movimiento de considerar las reglas y "costumbres" como una "justicia" o un "derecho" propio de las sociedades indígenas. La autora descarta la forma en que el Banco Interamericano de Desarrollo - BID ha implementado un proyecto global que se propone "positivizar estos derechos", es decir, transformarlos en un catálogo de normas extraídas de las culturas y leídas a partir de un marco universal desde la óptica de un derecho positivo occidental. ${ }^{18}$ Esa positivación, como vengo argumentando aquí y como Sánchez Botero señala, es una falsa comprensión de lo que esas normas son y significan en el seno de las comunidades en las que se originaron. Y esa falsa comprensión, en el campo del género, nos lleva a abominaciones escrupulosas de los enunciados del mundo del otro. Una hermenéutica de la propia norma es lo que aquí se torna indispensable, y lo que no tenemos.

No ha sido frecuente el foco de los etnógrafos sobre este fenómeno, que aquí intento cercar, de la captura y desarraigo de la norma y, en especial, de las normas que construyen el género, como proceso inherente a la intervención del frente blanco, para incluirla en el nuevo conjunto de relaciones. Tampoco contamos con etnografías de la vida sexual del mundo amerindio. He mencionado diversas veces, más arriba, el hecho de que la sexualidad $y$, en especial, la masculinidad amerindia se ve afectada por la exposición a los patrones de virilidad de la sociedad dominante. También listé la pedagogía pornográfica que hace su efecto, introduciendo la mirada alienada, objetificante y fetichizadora sobre el cuerpo. A esto se agrega la moralización de la sexualidad, introducida por la asociación entre mal y sexo, entre daño y sexo, el "pecado". El acceso sexual pasa a tener la connotación de profanación y apropiación. El cuerpo pasa a ser no solamente un territorio accesible, sino también expropiable y objeto de rapiña. Algunos ejemplos nos ayudan a exponer el nudo de estos cambios, verdaderas mutaciones para cuya descripción no tenemos todavía construida una capacidad retórica ni un vocabulario que nos permita examinar y exponer las pérdidas y las ganancias que nos imponen. Solo tenemos el vocabulario que la colonial/ modernidad, con su grilla cognitiva emergida como episteme después de la conquista, nos ofrece. Y ese vocabulario resulta insuficiente cuando tenemos que ver los cambios en su profundidad estructural. ${ }^{19}$

En un experimento de "antropología reversa" entre los indígenas Matis de la Tierra Indígena Vale do Javari, en el Estado de Amazonas, que Bárbara Maisonnave Arisi expone en su artículo "Vida Sexual dos Selvagens (Nós): Indígenas Pesquisam a Sexualidade dos Brancos e da Antropóloga", la autora nos cuenta el efecto causado por la llegada de películas pornográficas a aldeas extremamente distantes de los grandes centros:

En la aldea Aurelio, una de las transformaciones había sido provocada por la existencia de una placa solar que antes era usada para la iluminación de la escuela y ahora estaba conectada a un conversor y una batería de camión que proveía así de energía

18 SÁNCHEZ BOTERO, 2001, p. 190-191.

${ }^{19}$ Ver una crítica a los feminismos que tienen una comprensión universalista de la sexualidad en BIDASECA, 2011 
una televisión y un aparato de DVD. En la otra aldea, siete horas de canoa con motor 8HP río Ituí abajo, la televisión y el DCD eran alimentados por un generador movido a combustible - llamado 'combustol' en el Amazonas. En ambas TVs, uno de los programas era asistir películas pornográficas compradas o trocadas en las ciudades de Atalaia do Norte, Benjamin Constant o Tabatinga (AM), en Brasil, o en Leticia, Colombia. ${ }^{20}$

Recomiendo a todos el relato de la autora sobre ese encuentro del ojo indígena con la pornografía: la sorpresa, la perplejidad, la curiosidad, el asombro de los Matis frente a las escenas que, en comunidad, viejos, adultos, jóvenes y niños, atónitos, veían cada tarde intentando descifrar en qué consistía todo aquello que entendieron como "sexo de blanco". Pero hay que entender que no se trata, como enfatiza la autora que cito, solamente de una diferencia relativa a las formas que la propia práctica sexual asume (posiciones, etc.), sino a la relación misma de los sujetos con su sexualidad y con el cuerpo, aproximándonos aquí de alguna forma a las distintas pedagogías del sexo que emanan de la diferencia señalada por Foucault entre una "ars erótica", con su énfasis en la experiencia del placer, y una "scientia sexualis", con su énfasis en la representación y en la exterioridad. ${ }^{21}$ Está sugerida también aquí la diferencia entre el sexo como goce fálico de poder apropiador y administrador - perverso, en un lenguaje lacaniano -, y el sexo como placer de relación neurótico, para Lacan. Aquí se distinguen la pornografía del erotismo: el goce de un sujeto exterior que fantasía la apropiación del cuerpo explorado y explotado, como diferente al placer de la conjunción en que la entrega es compartida.

La exterioridad de la mirada pornográfica y perversa sobre el cuerpo y la representación focalizada y objetivada de sus placeres se encuentran asociadas a la exterioridad colonial moderna - exterioridad de la racionalidad científica, exterioridad rapiñadora de la naturaleza, exterioridad administradora de los recursos, exterioridad expurgadora del otro y de la diferencia, ya apuntadas por Aníbal Quijano y por Walter Mignolo, en sus textos y que aquí traduzco en términos de ese carácter pornográfico de la mirada colonizadora. ${ }^{22}$ La implantación de esa mirada exterior, pornográfica, alienadora del cuerpo y de la sexualidad y su importancia en la expansión del proceso colonial se muestran también en el hecho de la coincidencia, que no podré examinar aquí en toda la profundidad y densidad de sus afinidades, entre los grandes emprendimientos extractivos y la presencia de burdeles: se revela aquí una relación expropiadora y apropiadora, rapiñadora y exterior con el medio ambiente natural y con respecto al cuerpo femenino. He recibido también el relato de que cuando los jóvenes de comarcas patagónicas con gran presencia de población indígena Mapuche, en Argentina, migran a las cabeceras regionales reclutados como soldados en los cuarteles, el primer paso de su absorción en el nuevo medio es llevarlos a los burdeles de las inmediaciones del destacamento en el que recibirán entrenamiento militar. En consonancia con esto, es interesante que, después de la prohibición de los prostíbulos en la ciudad de Buenos Aires en 1935 y en toda la Argentina en 1936, con la ley 12.331, éstos vuelven a permitirse en 1944 solamente en las proximidades de los cuarteles militares. ${ }^{23}$ Una vez más estamos frente a la pedagogía de la mirada pornográfica sobre el cuerpo-objeto de las mujeres. Una pedagogía del festín sacrificial del cuerpo consumido como alimento del pacto entre los hombres que así, frente a sus restos, se concelebra y consolida. Pedagogía necesaria de insensibilidad, bloqueo de la empatía y distancia rapiñadora, para generar el esprit-de-corps de la hermandad

${ }^{20}$ Maisonnave ARISI, 2012, p. 56, mi traducción del portugués.

${ }^{21}$ Michael FOUCAULT, 1990.

${ }^{22}$ QUIJANO 1992; Walter MIGNOLO 2003, 2000.

${ }^{23}$ Raúl SCHNABEL, 2009. 
masculina ${ }^{24}$. Poco importa aquí si, como Lacan afirma al referirse a la pulsión escópica y la "mirada", no es el observador y sí el objeto mirado el que captura, es decir, el agente, el activo en colocar el ojo en foco, revelar su deseo (1978). E importa poco porque para colocarse efectivamente en ese lugar, el objeto debe, por su parte, objetificar la mirada del espectador, enseñarle a desear desde afuera, desde la falta, y ser capaz de secuestrarla y educarla a dirigirse a lo que exhibe. A pesar de activo, el "objeto" de la mirada que, a su vez, la objetifica, se encuentra, por lo tanto, cautivo y obligado a comportarse como sujeto eficiente de esta pedagogía de la crueldad que es la pedagogía del mirar pornográfico. Desde este punto de vista, esta modalidad de mirar faltante y faltoso es plenamente histórica. ${ }^{25}$

En la misma dirección de lo dicho va el ejemplo de lo sucedido con el antiguo ritual xavante de dar el nombre a las mujeres. La película 'Pi'ónhitsi', Mulheres Xavante sem Nome, de 2009, producida por Video en las Aldeas - VNA y dirigida por Tiago Campos Torres y Divino Tserewahú, muestra este cambio, esta mutación moral y normativa a la que vengo refiriéndome. Se relata allí la dificultad de la aldea Sangradouro, de Mato Grosso, para filmar una película sobre ese ritual de iniciación femenina, realizado por última vez completo en 1977. La dificultad resulta de que el Pi'ónhitsi prescribe que, durante la larga fiesta, el hermano del marido tenga acceso sexual a la mujer iniciante, siendo esto aceptado como una honra por el propio marido y su joven mujer. Como consecuencia de la presencia de una misión católica en la aldea, la mirada ya catequizada es inoculada con el veneno de la mirada occidental y surge la culpa y la deshonra. El ritual entonces es realizado nuevamente una vez durante los años 80 y por última vez en 1995, pero, por incidencia de los sacerdotes católicos, ocultando o retrabajando su verdadero guión original, para ser después definitivamente abandonado, en la consciencia de la lectura que el blanco haría del mismo. El ojo xavante aprende a ver el mundo, su propio mundo, con el ojo del blanco. Desde entonces, las mujeres quedarán sin nombre, pues es a través del Pi'õnhitsi que el nombre les era dado.

Una conversación entre su director indígena, Divino, y su director blanco, Tiago Torres, en la mesa de montaje, mientras repasan imágenes de archivo, es reveladora. Divino va pasando revista a algunas memorias de su vida, y relata al co-director, frente a la cámara, que durante su clausura en la casa de los hombres - llamada Ro entre los Xavante - para pasar por el proceso de iniciación masculina, le llamaba la atención que, además de su madre, otra mujer le llevaba su comida hasta el recinto. En una de sus salidas del resguardo, le preguntó a su madre quién era esa mujer, a lo que ésta respondió revelándole que era de la casa de su tío paterno que aquella comida provenía. Fue así que Divino se enteró de que su paternidad biológica era de su tío y no del marido de la madre. Recuerda, entonces, su reacción ante el relato de ella: "Soy un hijo de puta, ientonces!" fue su respuesta, rechazada sin dudar tanto por su madre como por su padre, marido de ésta, que le dicen: "No, no es así. Entre nosotros, las cosas son de otra manera". Es en esa exclamación, considero, que se encuentran encriptadas todas las contradicciones entre el patriarcado de bajo

${ }^{24}$ Sin duda hace eco aquí la mirada de los públicos occidentales frente a las exhibiciones de los vasos mochicas en los museos del mundo. Es una mirada pornográfica sobre escenas que son plenamente eróticas y que nada tienen que ver con la malicia que esas audiencias les atribuyen, ya que lo que exponen es una celebración de la vida y del placer sin componente de daño.

${ }^{25}$ Kaja SILVERMAN (1992, p. 407) me parece confirmar esta historicidad cuando, en una nota, cita un comentario de Lacan a respecto de la conversión auto-consciente de esta mirada, que se torna explícita: "I saw myself seeing myself" ... [this formula] remains ... correlative with that fundamental mode to which we referred in the Cartesian cogito..." Nadie dudaría hoy de que el cogito cartesiano es un viraje plenamente histórico. 
impacto propio del mundo-aldea, comunitario, y el patriarcado perverso de la colonial / modernidad apropiadora, pues en el contexto del Pi'ônhitsi no existe mirada pornográfica, es decir, no existe accesibilidad sexual expropiadora y causa de deterioro moral, en el sentido que revela la mirada, confusa ante su propia colonización, del cineasta indígena. De esta forma, la aldea quiere hoy recuperar el ritual Pi'ónhitsi, pero el mayor obstáculo que enfrenta viene de los jóvenes maridos de las mujeres que tendrían que participar del mismo. Estos jóvenes hombres han aprendido a entender el cuerpo de sus esposas con una mirada pautada por los valores de la virilidad del colonizador. Es el hombre blanco su interlocutor y par preferencial en el presente, de la mano de ese interlocutor dominante, el ombligo del cosmos se va desplazando de la aldea hacia el mundo del blanco, y es la fragilidad de los hombres, tan fácilmente cooptables por el mundo dominador, que lo permite.

Pero el mundo blanco, con su prejuicio y pecado, con su visión del sexo como daño, mácula, reducción y sujeción del otro penetrado, feminizado, opera indudablemente con un doble estándar de moralidad. Su moral no es consistente. Un caso que ha dividido a las antropólogas feministas en Argentina expone de forma muy clara ese doble estándar. Se trata del caso de la muchacha wichí, en la región del chaco salteño, tomada como esposa por el marido de su madre, con el consentimiento de ambas. Denunciado por la directora de la escuela en que la niña estudiaba, la historia de un "padrastro violador" del pueblo Wichi recorrió el país y provocó un enfrentamiento feroz entre las antropólogas que trabajan sobre el tema de género. El feminismo universalista afirma que el acceso sexual del marido de la madre sobre una menor de edad es crimen en todos los casos y para cualquier sociedad. El feminismo decolonial afirma que es necesario escuchar lo que dice la gente, y de hecho, durante los siete años que el joven marido de ambas mujeres wichi permaneció preso, fueron éstas quienes le llevaron su comida diariamente a la cárcel, porque el acceso sexual no tiene para las mujeres wichi el mismo significado que tiene para nosotros, y porque para los Wichi dos mujeres pueden compartir un hombre. Todavía una información complementar se torna indispensable para revelar el sentido oculto del empeño de los agentes estatales en criminalizar al joven marido wichi: en esa región existe la costumbre del "chineo", es decir, de la iniciación sexual de jóvenes criollos mediante la violación de las niñas wichis de las aldeas próximas. Sucede que, muy a la inversa de lo ocurrido respecto a la supuesta "violación" de la niña wichi por su padrastro, cuando las niñas wichis son violadas por hombres criollos, el estado es omiso y la impunidad es garantizada. Aquel empeño mostrado por velar por la integridad sexual de las niñas indígenas frente a los hombres también indígenas, encarcelándolos sin oír los argumentos del propio pueblo, se desvanece y deja lugar a la omisión y la indiferencia cuando el agresor de las muchachas indias es el hombre blanco. ${ }^{26}$ La hipocresía de la mirada del blanco sobre el indio queda, de esta manera, expuesta.

La diferencia que aquí intento mapear entre la función normativa y su impacto en el control del género y la sexualidad muestra su relevancia hasta en los casos en que la propia sobrevivencia del grupo está en juego. Esto se demuestra en el relato que recibí en 2009, durante una reunión de la Coordinación de Género de la Fundación Nacional del Indio en Tangará da Serra, Mato Grosso, para la divulgación de la Ley Maria da Penha contra la violencia doméstica, de una mujer indígena tapuia de la Aldea Carretão, Estado de Goiás, nacida en 1952. Al inquirir sobre su piel blanca, cabellos ondulados y apariencia europea, Ana Lino Tapuia, mi compañera de habitación en el hospedaje que ocupábamos, me explicó que sus rasgos físicos son el resultado del proceso de reconstrucción de su

${ }^{26}$ Ver Alejandra CEBRELLI, 2007; Elena CORVALÁN, 2011; y BIDASECA, 2011. 
pueblo. Una variante de esa historia, me aclaró, aunque no exactamente igual, había sido ya relatada por su propia madre, décadas atrás, a la antropóloga Rita Heloisa de Almeida Lazarin, que la registró, según constaté, en tesis y publicaciones. ${ }^{27}$ Ciertamente, la historia que recogí en Tangará da Serra, por efecto del pudor colonial, difiere y complementa la historia oficial de los Tapuio, cuya síntesis se difunde en la importante página web de divulgación etnográfica del Instituto Socio-Ambiental de Brasil. ${ }^{28}$ De acuerdo con el extraordinario relato de Ana Lino, los Tapuio, que habían sido uno de los pueblos más numerosos en tiempos de la irrupción portuguesa, después de las guerras y masacres llegaron a su casi extinción por una serie de epidemias que les asestaron lo que pareció ser el golpe de gracia. De la secuencia de infortunios restaron solamente tres mujeres vivas en las primeras décadas del siglo XX, una de ellas la bisabuela de Ana Lino. Frente a la inminencia de un final del mundo al que pertenecían, las tres pusieron en práctica una estrategia que les permitió vencer la muerte, personal y colectiva. Esta estrategia consistió en practicar conjunción carnal con todo forastero, de cualquier origen y color, que atravesase sus tierras. Hombres blancos, xavantes y negros fueron de la misma forma abordados y convocados a la tarea de procrear y así reconstruir las bases demográficas que permitieran rehacer el pueblo Tapuio, hasta que la garantía de su continuidad y condición de ocupar el territorio que les fuera concedido por la corona portuguesa a fines del siglo XVII les diera descanso. Hoy, con alrededor de 300 miembros, la comunidad se encuentra fuera de peligro y continúa en franca expansión, a pesar de la pobreza.

En esta extraordinaria historia resalta, por un lado, la capacidad de las mujeres de administrar su propia sexualidad, es decir, su agencia y soberanía sexual y procreativa, y la suspensión total e irrestricta de todos los parámetros que hoy consideramos constituir la normativa positiva de un cultura: reglas de conyugalidad y parentesco, creencias respecto de la vida y sus prácticas procreativas, nociones de identidad que colocan barreras entre sociedades, etc. Las tres regeneradoras del mundo Tapuio abjuraron deliberada y estratégicamente de todos los contenidos que sirven de referencia para lo que conocemos como etnicidad, y la identidad e identificaciones que de ella se derivan, y trabajaron estrictamente por un proyecto como pueblo obedeciendo a una pulsión de futuro colectivo a partir de la conciencia de un pasado común. El vector aquí es la propia idea de ser un pueblo en busca de continuidad.

Otras sociedades se han visto también frente a la muerte como sujetos colectivos, y se han rescatado a sí mismas de esa dramática circunstancia por medio de estrategias semejantes. Los Tapirapé de Mato Grosso se vieron reducidos a 56 personas en los años 70 , y hoy son aproximadamente mil. De los Avá-Canoeiro de Tocantins sobrevivieron 11 y hoy son 20 personas, algunas de ellas hijas de lo que llamaríamos violación o de relaciones incestuosas. Sus madres, sin embargo, nunca les hablaron sobre esto, pues es la determinación de reconstruirse como pueblo lo que consideraron relevante.

\section{Género y colonialidad: del patriarcado de bajo impacto al patriarcado moderno}

He iniciado mi exposición con un listado de formas de agresión padecida por las mujeres indígenas a medida que avanza el frente estatal-empresarial-mediático-cristiano que no deja dudas de la participación del Estado en los daños infringidos. He argumentado que todos los esfuerzos en términos de legislación, políticas públicas y acciones estatales

${ }^{27}$ Rita Heloisa de Almeida LAZARIN, 1985 y 2003.

28 INSTITUTO SOCIO-AMBIENTAL, 2009. 
poco pueden contra esta máquina arrolladora que avanza sobre las comunidades, pues la protección que ensaya el estado y sus agentes va a remolque de la destrucción que este mismo estado impone a los pueblos. He tratado hasta aquí de la transición de lo que he llamado "mundo-aldea", a falta de un nombre mejor para representar las relaciones sociales antes de la intrusión colonial, al mundo intervenido por la administración colonial primero ultramarina y después republicana, colocando el foco en la mutación de la concepción de la norma, y en especial de las normativas de género y sexualidad.

Mis observaciones son el resultado de un período de diez años de observación de la expansión del frente estatal "democrático" en el mundo indígena de Brasil y en la vida de las mujeres. El frente estatal "democrático" al que hago referencia es el de las post-dictaduras en nuestros países, que llega a la frontera indígena, al "mundo-aldea", con leyes y políticas públicas, empresas y ONGs. Ese frente, siempre colonial, irremediablemente intrusivo e interventor en lo que resta del mundo-aldea, intenta entregar con una mano lo que ya ha retirado con la otra, se esfuerza en ofrecer antídotos, bajo la forma de derechos, para contener la acción del veneno que ya inoculó. Debido al formato constitutivo del Estado y la baja consciencia entre sus agentes de la diferencia entre la "ciudadanía" como masa de individuos formalmente titulares de derechos y una organización comunitaria y colectivista de la vida, la consecuencia de su accionar es, casi inevitablemente, disruptiva con respecto al tejido de relaciones y sistema de autoridad propio del mundo-aldea, además de producir el seccionamiento de los hilos de la memoria de sus miembros. He visto ese proceso desdoblarse, expandirse y afectar la vida de las mujeres a través de una forma de infiltración específica, como es el de las relaciones de género del orden colonial moderno en las relaciones de género en el mundo-aldea; he comprendido la torsión radical introducida por la entrada del tiempo colonial/moderno en la historia de las relaciones de género.

Datos documentales, históricos y etnográficos del mundo tribal, muestran la existencia de estructuras reconocibles de diferencia, semejantes - pero no idénticas - a lo que llamamos relaciones de género en la modernidad, determinando jerarquías claras de prestigio entre la masculinidad y la feminidad, representadas por figuras que pueden ser entendidas como hombres y mujeres. A pesar del carácter reconocible de las posiciones de género, en ese mundo son más frecuentes las aberturas al tránsito y circulación entre esas posiciones que se encuentran interdictas en su equivalente moderno occidental. Como es sabido, pueblos indígenas, como los Warao de Venezuela, Cuna de Panamá, Guayaquís (Aché) de Paraguay, Trio de Surinam, Javaés de Brasil y el mundo incaico pre-colombino, entre otros, así como una cantidad de pueblos nativo-norte-americanos y de las primeras naciones canadienses, además de todos los grupos religiosos afro-americanos, incluyen lenguajes y contemplan prácticas transgenéricas estabilizadas, casamientos entre personas que el Occidente entiende como siendo del mismo sexo, y otras transitividades de género bloqueadas por el sistema de género absolutamente enyesado de la colonial/modernidad. ${ }^{29}$ También son reconocibles, en el mundo pre-intrusión, las dimensiones de una construcción de la masculinidad que ha acompañado a la humanidad a lo largo de todo el tiempo de la especie, en lo que he llamado "pre-historia patriarcal de la humanidad", caracterizada por una temporalidad lentísima, es decir, de una longue-durée que se confunde con el tiempo evolutivo. ${ }^{30}$ Esta masculinidad es la construcción de un sujeto obligado a adquirirla como status, atravesando probaciones y enfrentando la muerte -

${ }^{29}$ Para una lista de identidades transgenéricas en sociedades históricas y contemporáneas ver CAMPUZANO, 2009a.

${ }^{30}$ SEGATO, 2003b.

612 Estudos Feministas, Florianópolis, 22(2): 593-616, maio-agosto/2014 
como en la alegoría hegeliana del señor y su siervo. Sobre este sujeto pesa el imperativo de tener que conducirse y reconducirse a ella a lo largo de toda la vida bajo la mirada y evaluación de sus pares, probando y reconfirmando habilidades de resistencia, agresividad, capacidad de dominio y acopio de lo que he llamado "tributo femenino" ${ }^{31}$ para poder exhibir el paquete de potencias - bélica, política, sexual, intelectual, económica y moral que le permitirá ser reconocido y titulado como sujeto masculino.

Por lo tanto, contrariamente a lo que han afirmado otras autoras también críticas de la colonialidad, ${ }^{32}$ el género me parece existir en sociedades pre-coloniales, pero lo hace de una forma diferente que en la modernidad. Como he argumentado aquí, cuando esa colonial modernidad se le aproxima al género de la aldea, lo modifica peligrosamente, interviene su estructura de relaciones, las captura y las reorganiza desde dentro, manteniendo la apariencia de continuidad pero transformando los sentidos. Se da entonces, como dije, un efecto de vero-similitud, ya que las nomenclaturas permanecen, pero son reinterpretadas a la luz del nuevo orden moderno. Algo semejante ha apuntado Julieta Paredes con su idea del "entronque de patriarcados". ${ }^{33}$

Esta cruza es realmente fatal, porque un idioma que era jerárquico, en contacto con el discurso igualitario de la modernidad, se transforma en un orden súper-jerárquico y desarraigado, debido a:

- la emasculación de los hombres en el ambiente extra-comunitario, frente al poder de los administradores blancos, que requiere reconstrucción mediante el uso de violencia;

- la hiperinflación de los hombres en el ambiente comunitario, por su papel de intermediarios con el mundo exterior, es decir, con la administración del blanco, con quien hace la guerra y negocia recursos;

- la transmutación del espacio público, habitado ancestralmente por los hombres, en una esfera pública que secuestra para sí toda la politicidad y se vuelve, de esta forma, inflacionada y pretendidamente universal, siendo sus leyes positivadas;

- el derrumbe, la privatización y nuclearización del espacio doméstico, transformado ahora en resto y margen desprovisto de politicidad;

- la binarización de la dualidad que estructura el género en el mundo-aldea, con totalización de uno de sus dos términos cuando constituido como público y universal, en oposición a otro, constituido como privado, particular y marginal: relaciones de complementariedad duales se han convertido en relaciones binarias en que uno de los términos es suplementar;

- Ia individualización y masificación de un mundo que fue compartimentalizado, subdividido por categorías de género con sus espacios colectivos propios;

- la inoculación del ojo pornográfico, concepto que resume la mirada exterior y objetificante así como la comprensión del acceso sexual como daño, profanación y apropiación.

Ha surgido una reflexión entre feministas en América Latina sobre el papel que juega el género y la sexualidad en la instauración y profundización del patrón de la colonialidad del poder, advirtiendo una fragilidad de esa perspectiva teórica hasta el momento en lo que respecta a la ecuación del género). ${ }^{34}$ También Francesca Gargallo, en su examen de

${ }^{31}$ SEGATO, 2003b.

32 María LUGONES, 1997; Oyeronke OYEWUMI, 2007, entre otras.

33 Julieta PAREDES, 2010

${ }^{34}$ Ver, muy especialmente, Breny MENDOZA, 2013. 
lo que entiende como sistema racista-sexista de origen colonial pero con desdoblamientos posteriores a las independencias nacionales, ha desarrollado esta crítica levantando las voces de las mujeres indígenas del continente. ${ }^{35}$

Por mi parte, he examinado este proceso por extenso en mi texto "Género y Colonialidad" (2013), para concluir invirtiendo la máxima "diferentes pero iguales" de los derechos humanos, que expresa su propósito de universalizar la ciudadanía mediante la expansión de la égida estatal. Al sopesar las pérdidas y las ganancias que resultan de la captura de las instituciones del mundo-aldea por las del mundo del blanco, concluyo que, en el "desiguales pero distintos" de la comunidad no intervenida, es decir, en la posibilidad de la diferencia no constituida como problema, radica un nuevo punto de partida.

\section{Referencias}

ÁLVAREZ DEGREGORI, María Cristina. Sobre la mutilación genital femenina y otros demonios. Barcelona: Publicacions d'Antropologia Cultural. Universitat Autònoma de Barcelona, 2001.

BIDASECA, Karina. "Mujeres blancas que buscan salvar a las mujeres color café de los hombres color café. Desigualdad, colonialismo jurídico y feminismo postcolonial". Andamios Revista de Investigación Social, Universidad Autónoma de la Ciudad de México, México, D.F., v. 8, n. 17, set./dic. 2011.

BUENO SARDUY, Aida. El ocaso del sacerdocio femenino en el xangô de Recife: la "ciudad de las mujeres" que no será. Tesis de Doctorado a ser defendida en el Programa de Antropología de la Universidad Complutense de Madrid.

CENTRO INDIGENISTA MISSIONÁRIO. Relatório violência contra os povos indígenas no Brasil dados de 2011. Brasília: CIMI/Adveniat, 2011.

CARVALHO, Maria Rosário de. Revista Coletiva, n. 10, jan./fev./mar./abr. 2013.

CEBRELLI, Alejandra. "El caso de la niña wichi en la prensa: violencia y exclusion detrás de los discursos sobre la igualdad". Diagonal. Psicoanálisis y cultura, v. 4, n. 14, 2007.

CORVALÁN, Elena. "La 'Costumbre' de violar niñas Wichi." Reflexiones Marginales, n. 16, 11 Sept. 2011 . Disponible en: <http://v2.reflexionesmarginales.com/index.php/cronicas-defrontera/204-practicas-de-dominacion>. Acceso en: 25 ago. 2013.

DAL POZ, João; JUNQUEIRA, Carmen. "Cinta Larga". Povos Indígenas no Brasil, Brasília: Instituto Socio-Ambiental - ISA, 2013.

Disponible en:<http://pib.socioambiental.org/pt/povo/cinta-larga>. Acceso en: $1^{\circ}$ agosto 2013.

FOUCAULT, Michel. The History of Sexuality. An Introduction, Penguin Books, 1990. vol. 1.

FRANCHETTO, Bruna. "Mulheres entre os Kuikúro". Revista de Estudos Feministas. v. 4, n. 1, p. 35-54, 1996

."Apresentação". Revista de Estudos Feministas, v. 7, n. 1-2, p. 141-142, 1999.

GARGALLO CELENTANI, Francesca. Feminismos desde Abya Yala. Ideas y proposicioens de las mujeres de 607 pueblos en Nuestra América, Bogotá: Ediciones Desde Abajo, 2012.

GOT, Gil. "Imperial Humanitarianism: History of an Arrested Dialectic". In: HERNÁNDEZ-TRUYOL, Berta Esperanza (Ed.). Moral imperialism: a critical anthology. New York: New York University Press, 2002.

\footnotetext{
${ }^{35}$ Francesca GARGALLO, 2012. Otros ejemplos en la misma dirección merecen mención aquí, como las tesis recientemente defendidas de Karina OCHOA (2011) y Silvana SCIORTINO (2013). También la tesis doctoral que prepara Aida Buenos SARDUY, que muestra cómo, junto a la expansión de la égida colonial-estatal modernizadora en los terreros de religión afro-brasilera, las mujeres van perdiendo la posición de autoridad que siempre han tenido en ese medio (Bueno SARDUY [s./d.]).
}

614 Estudos Feministas, Florianópolis, 22(2): 593-616, maio-agosto/2014 
INSTITUTO SOCIO-AMBIENTAL. "Povo Tapuio". Enciclopédia Povos Indígenas no Brasil. Brasília: ISA, 2009. Disponible en: <http://pib.socioambiental.org/pt/povo/tapuio/1016>. Acceso en: 25 oct. 2009.

LACAN, Jacques. The Four Fundamental Concepts of Psycho-Analysis. New York: Norton, 1978.

LASMAR, Cristiane. "Mulheres indígenas: representações". Revista de Estudos Feminista, Florianópolis, v. 7, n. 1-2, p. 143-156, 1999.

De volta ao lago de leite: gênero e transformação no Alto Rio Negro. Sao Paulo: Editora UNESP/ ISA, 2005.

LAZARIN, Rita Heloisa de Almeida. O aldeamento do Carretão: duas histórias. 1985. Tesis (Maestría en Antropologia Social) - Departamento de

Antropologia, Universidade de Brasília, Brasília.

Aldeamento do Carretão segundo os seus herdeiros tapuios: conversas gravadas em 1980 e 1983, Brasilia: FUNAI/DEDOC, 2003.

LEA, Vanessa Rosemary. "Desnaturalizando gênero na sociedade Mebengôkre". Revista de Estudos Feministas. Número duplo - Dossiê Mulheres Indígenas v. 7, n. 1-2, p. 176-194, 1999.

LUGONES, María. "Heterosexualism and the Colonial / Modern Gender System." Hypatia, v. 22, no. 1, p. 186 -209, Winter, 2007.MCCALLUM, Cecília. "Aquisição de gênero e habilidades produtivas: o caso Kaxinawá". Revista de Estudos Feministas, v. 7, n. 1-2, p. 157-175, 1999.MAISONNAVE ARISI, Bárbara. "Vida sexual dos selvagens (nós): indígenas pesquisam a sexualidade dos brancos e da antropóloga". In: SACCHI, Ángela; GRAMKOW, Marcia Maria: Gênero e Povos Indígenas. Brasília/ Rio de Janeiro: Museu do Índio - e GIZ, 2012.MENDOZA, Breny. Ensayos de crítica feminista en Nuestra América, Ciudad de Mexico, DF: Editorial Herder, 2013. En prensa.MIGNOLO, Walter. Histórias Locais /Projetos Globais. Belo Horizonte: Editora UFMG, 2003 [2000].

OCHOA MUÑOZ, Karina. La lucha del pueblo Nanncue Ñomndaa: un camino hacia la constitución de nuevos sujetos políticos indígenas femeninos. El caso de Xochistlahuaca, Guerrero, Posgrado en Desarrollo Rural, Universidad Autónoma Metropolitano, 2011.

OYEWUMI, Oyeronke. The Invention of Women. Making an African Sense of Western Gender Discourses. Minneapolis: University of Minnesota Press, 2008.

PAREDES, Julieta. Hilando fino desde el feminismo comunitario. 3. ed. La Paz: CEDEC y Mujeres Creando Comunidad, 2010.

QUIJANO, Aníbal. "La modernidad, el capital y América Latina nacen el mismo día", entrevista dada a Nora Velarde. ILLA - Revista del Centro de Educación y Cultura, Lima, n. 10, p. 4257, enero, 1991a.

. "Colonialidad y Modernidad/Racionalidad", Peru Indigena, v. 13, n. 29, Lima (republicado en Bonilla, H. (Comp.): Los conquistados. 1492 y la población indígena de las Américas, Quito, Tercer Mundo/ Libri Mundi/FLACSO-Ecuador). 1991b

RODRIGUES, Patrícia de Mendonça. O Povo do Meio: tempo, cosmo e gênero entre os Javaé da Ilha do Bananal. 1993. Dissertação de Mestrado - Universidade de Brasília.

. "O surgimento das armas de fogo: alteridade e feminilidade entre os Javaé". Revista de Estudos Feministas, v. 7, n. 1- 2, p. 195-205, 1999.

. A caminhada de Tanyxiwè - uma teoria Javaé da História. PhD Thesis. 2008. Department of Anthropology, Universidade de Chicago.

SACCHI, Angela. "Mulheres Indígenas e Participação Política: a discussão de gênero nas organizações de mulheres indígenas". Anthropológicas, v. 14, p. 105-120, 2003.

SÁNCHEZ, Botero. "Aproximación desde la antropologia jurídica a la justicia de los pueblos indígenas", en Sousa Santos, Boaventura de y Mauricio García Villegas (Eds.): El Caleidoscopio de las Justicias en Colombia. Bogotá: Siglo del Hombre Editores, 2003. Tomo II. 
SCHNABEL, Raúl A. Historia de la trata de personas en Argentina como persistencia de la esclavitud. Buenos Aires: Dirección General de Registro de Personas Desaparecidas, 2009. Disponible en: <www.mseg.gba.gov.ar/Trata/HISTORIA.pdfý> . Acceso en: 12 agosto 2013.

SCIORTINO, Silvana. Una etnografía en los Encuentros Nacionales de Mujeres: políticas de identidad desde la afirmación de las 'mujeres de los Pueblos originarios'. 2002. (Tesis doctoral inédita). IdIHCS, Centro Interdisciplinario de Investigaciones en Género, FAHCE, Universidad Nacional de La Plata.

SEGATO, Rita, Uma agenda de ações afirmativas para as mulheres indígenas indígenas do Brasil. Nova Edição. Brasília: Departamento de Antropologia, Universidade de Brasília/ Fundação Nacional do Índio - Funai/ Deutsche Gesellschaft fur Technische Zusammenarbeit - GTZ, 2003a. (Série Antropologia, 326).

. Las Estructuras Elementales de la Violencia. Buenos Aires: Prometeo, 2003b.

. Territorio, soberanía y crímenes de Segundo Estado: La escritura en el cuerpo de las mujeres asesinadas en Ciudad Juárez. México, DF: Ediciones de la Universidad del Claustro de Sor Juana, 2006.

. "Femi-geno-cidio como crimen en el fuero internacional de los Derechos Humanos: el derecho a nombrar el sufrimiento en el derecho". In: FREGOSO, Rosa-Linda; BEJARANO Cynthia (Eds.). Feminicidio en América Latina. México, DF: UNAM-CIIECH/Red de Investigadoras por la Vida y la Libertad de las Mujeres, 2011.

"Aníbal Quijano y la Colonialidad del Poder". In: La Crítica de la Colonialidad en Seis Ensayos. Buenos Aires: Prometeo, 2014a. En prensa.

. "Género y colonialidad: en busca de claves de lectura y de un vocabulario estratégico decolonial". Buenos Aires: Prometeo, 2014b. En prensa.

. "Que cada povo teça os fios da sua história: o pluralismo jurídico em diálogo didático com legisladores". DIREITO.UnB. Revista de Direito da Universidade de Brasília, v. 1, n. 1, 2014c.

VERDUM, Ricardo (Org.). Mulheres Indígenas, Direitos e Políticas Públicas, Brasília: INESC, 2008.

VINENTE DOS SANTOS, Fabiane. "Mulheres indígenas, movimento social e feminismo na Amazônia: empreendendo aproximações e distanciamentos necessários", Revista EDUCAmazônia, v. 8, n. 1, p. 94-104, 2012.

[Recebido em fevereiro de 2014 e aceito para publicação em abril de 2014]

\section{Sex and the Norm: State Front, Patriarchy, Dispossession and Coloniality}

In this article I examine the various effects of the expansion and intrusion of contemporaneous state - enterprise - media - Christianity front, ever colonial and also parastatal, into Brazilian indigenous communities - called village-world for the sake of the argument here -, and their consequences for the lives of women. After this overview, focus is placed on some cases and examples that reveal a shift in the understanding of sexuality and the meaning and value attributed to sexual access to bodies, as well as on a crucial change in the meaning of "norms" in precolonial intervention societies and in societies intervened by the colonization process - in Hispanic countries, the "criollo" society. Transformation of the sexual field by the introduction of the pornographic gaze emerge then as the pivot or rotation axis of the mutation of one world into the other. The alienated body-object, and colony emerge as coetaneous and akin in the new order in constant expansion. Dispossession, in this process, is, therefore, progressive dispossession of one's body and sexuality.

Key Words: State; Capital; Indigenous Women; Patriarchy; Sexuality; Norms; Coloniality.

616 Estudos Feministas, Florianópolis, 22(2): 593-616, maio-agosto/2014 